\title{
Sensitivity of Earthworm (Eisenia fetida) in Mining Soil from Ijero-Ekiti, Nigeria
}

\section{${ }^{* 1}$ AGBO, SO; ${ }^{1}$ MUSTAPHA, MA; ${ }^{1}$ OGAUGWU, CE; ${ }^{1}$ SODIPE, OG; ${ }^{2}$ CHUKWU, EC; ${ }^{1}$ RAJI, MF; ${ }^{3} \mathrm{NEBO}, \mathrm{UC}$}

\author{
${ }^{I}$ Department of Animal and Environmental Biology, Federal University Oye-Ekiti, Ekiti State, Nigeria \\ ${ }^{2}$ Department of Geology, Federal University Oye-Ekiti, Ekiti State, Nigeria \\ ${ }^{3}$ Department of Microbiology, Federal University Oye-Ekiti, Ekiti State, Nigeria \\ *Corresponding Author Email: sozoemena@hotmail.com; stanley.agbo@fuoye.edu.ng
}

\begin{abstract}
Excavation and processing of mineral deposits are valuable revenue sources yet they contribute serious environmental problems worldwide. Mining activities are widespread and contribute to heavy metal contamination in rural communities in Ekiti State, Nigeria. Available research failed to establish how mining soil may impact on resident terrestrial organisms. This study assessed the health of soil from active mining site by testing it on earthworms (Eisenia fetida) for 10 weeks. Survival, mobility, morphology and behaviour of worms were assessed while soil was analyzed for selected heavy metals by atomic absorption spectrometry. Worm survival was evident as the proportion of reference soil increased in exposure mixture and improved until $92 \%$ in the control. Worms curled up at the bottom of test vessels with varying proportions of mining site soil and appeared discolored and dehydrated when taken out of test soil, with characteristic sluggishness, particularly as the proportion of mining soil increased in exposure mixtures. Though metal levels were within permissible limits, morphology of exposed worms were visibly impacted, which corresponds in severity with increasing proportion of mining soil. On the contrary, worms tested in $100 \%$ reference soil appeared healthy and active in upper part of exposure vessels. These results suggest that the tested mining soil had adverse impacts on mobility, morphology, behavior and survival of exposed organisms when compared with the control population. Therefore, food products grown downstream of the mining site may be at risk of heavy metal contamination with consequences on food quality, water quality and food chain.
\end{abstract}

\section{DOI: https://dx.doi.org/10.4314/jasem.v25i4.19}

Copyright: Copyright $(0) 2021$ Agbo et al. This is an open access article distributed under the Creative Commons Attribution License (CCL), which permits unrestricted use, distribution, and reproduction in any medium, provided the original work is properly cited.

Dates: Received: 14 February 2021; Revised: 26 March 2021; Accepted: 12 April 2021

Keywords: earthworm, mining soil, heavy metal, toxicity, Ijero-Ekiti

Mining of mineral deposits is an essential revenue source for many countries including Nigeria. Large deposits of gold, bauxite, and cobalt contribute to Africa's ranking among countries with high reserves in various mineral deposits (Markwitz et al. 2016; Olade 2019). For instance, coal and petroleum reserves account for more than $90 \%$ of foreign exchange earnings for Algeria, Equatorial Guinea, Libya and Nigeria (Markwitz et al. 2016; Olade 2019). Despite the huge gains from mineral explorations, many developing countries have failed to invest profitably in environmental friendly excavations, processing and marketing of mineral deposits and their finished products. Due to obvious neglect, even regulated practices can lead to degradation of the natural environment. It is for this reason that mining has been referred to as a destructive developmental activity that drives economic boom at the expense of ecology (Chauhan, 2010). The challenge, however, in many developing countries including Nigeria is that a significant part of mining activities is highly unregulated and left in care of rural communities to spur conflicts among indigenous dwellers. Also, it is commonplace for certain community heads to illegally recruit miners in exchange for little returns. Such illegal practice exposes field persons to risks and substances of concern, since majority of them do not wear protective gears and professional kits. Apart from defaced landscape evidenced by existing deep trenches and pits that pose great risk to residents of rural communities, farmers strive to find prospective fertile land to grow their crops (Scullion, 2002; Mfon et al., 2014). Over time, runoffs and weathering of loose components contribute to denature and mobilize soils, thereby transporting them to active farmlands. Even more prominently, rural farmers cultivate different crops including tubers and vegetables, which unknown to them are in close proximity to the mining sites and can potentially accumulate hazardous chemicals. Apart from threat that accumulated chemical substances pose to human population and other organisms, they distort degradation processes in soil systems which contribute greatly to soil structure, fertility and ultimately yield of crops (Yvan et al., 
2012). Essential soil resident microbes, arthropods and macro invertebrates including earthworms are threatened by pollutants leaching from mining site soils. Even though some of these substances are beneficial in moderate quantities, they can induce adverse health effects in microbes and earthworms since exposures are in mixtures of the contaminating metals. Considering the recalcitrant nature of metallic contaminants, they can be transferred higher up in the food chain, apart from additional possibility to contaminate surrounding water bodies (Pachana et al., 2010). Many previous studies have assessed metal levels in soils (Sidhu, 2016; Akande and Ajayi, 2017). While majority of them focused on metal load in natural soils, others analyzed metal-spiked samples to investigate sorption and bioavailability processes in soil mixtures. Therefore, there is paucity of information on mobility, morphology and behaviour of indigenous invertebrates and earthworm exposed to mining site soil. The objectives of this study were to assess potential adverse consequences of exposure to mining soil mixtures on mobility, morphology, behavior and overall survival of earthworm under laboratory conditions. This experimental setup benefits from the fact that mucous secretions from earthworms may influence soil $\mathrm{pH}$, pollutant partitioning and desorption, bioavailability and accumulation in exposed organisms.

\section{MATERIALS AND METHODS}

Study area, soil and worm acclimatization: The study site is an active mining site in Ijero-Ekiti, Ekiti State, Nigeria. The site is located in North-West of Ekiti State with geographical coordinates of N07 ${ }^{\circ} 49.514^{\prime}$, E05 $^{\circ}$ 04.117' (etrex 10 GARMIN GPS device). In close proximity to the area is an agrarian community that produces cash crops, including cocoa, kolanut, cashew and timber. Food crops that include yam, cocoyam, pepper, tomatoes and banana are grown in large quantities. However, a great percentage of the agricultural landscape is rich in minerals including limestone, bauxite, copper, columbite, diamond, iron and even gold deposits, thus constitutes a great attraction for illegal miners. Soil sample was randomly collected across the landscape close to sites having active mining operations behind the Specialist Hospital Ijero-Ekiti (Figure 1). The soil was excavated from top soil within a depth of $40 \mathrm{~cm}$, wrapped in clean plastic bags and quickly transported in a sample box to the laboratory of Animal and Environmental Biology, Federal University Oye-Ekiti, Nigeria.

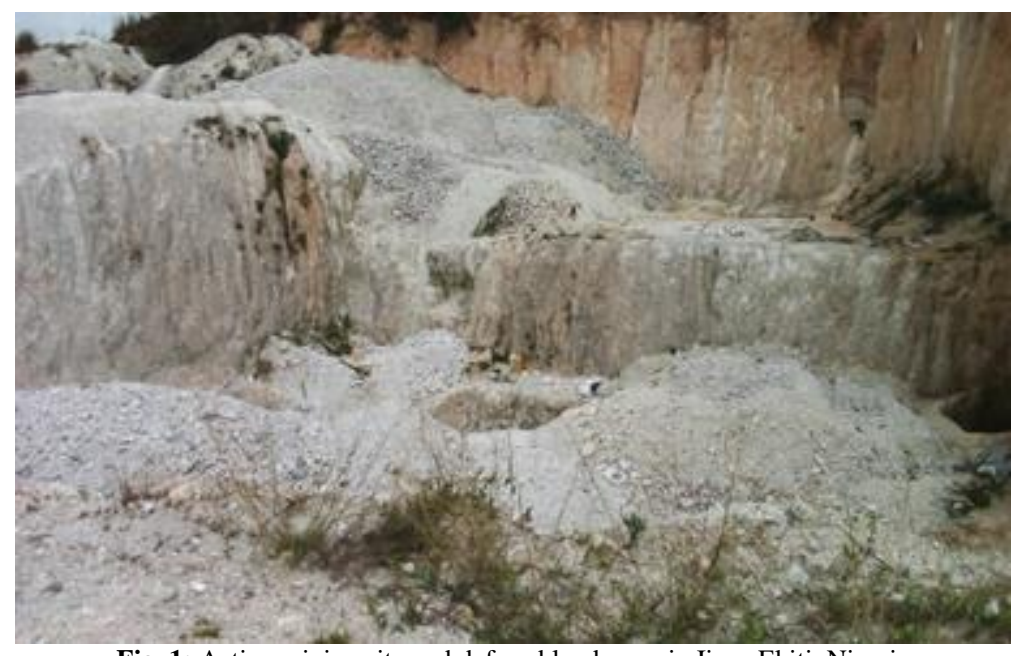

Fig. 1: Active mining site and defaced landscape in Ijero-Ekiti, Nigeria

On the other hand, the reference soil was taken from a site, $\mathrm{N} 07^{\circ} 46.481^{\prime}, \mathrm{E} 005^{\circ} 18.952^{\prime}$ that hardly has been impacted by human activity in the past 40 years, behind the Faculty of Science of the same University. Both soil types were stored safely in clean sacks in the laboratory until processing and exposure experiments.

Earthworm is a crucial model considering that it eats soil whole, commonly found in tropical soil and associated with soil health and fertility. Therefore, it is a good candidate for environmental risk assessment and bio-indicator organism for toxicity testing in soil (Ezeokoli et al., 2021). In this study, one hundred and sixty (160) adult earthworms were picked randomly from beneath the soil in a clean site beside Afuremu, Oye-Ekiti, Nigeria.

The worms were acclimatized in damp reference soil, secured in a large container and stored away at room temperature for 14 days prior to use. In addition to other physiological adjustments, this treatment step enables worms to empty their gut contents. 
Characterization and preparation of soils: Soils dried in open air were processed and characterized for several different parameters (Table 1). Soil samples were passed through a sieve having pore size diameter of $<5 \mathrm{~mm}$ to filter away debris and coarse stones.

\begin{tabular}{lll} 
Table 1: Characteristics of reference and & mining site soils \\
\hline Parameter & $\begin{array}{l}\text { Mining } \\
\text { soil }\end{array}$ & $\begin{array}{l}\text { Reference } \\
\text { soil }\end{array}$ \\
& White & Brown \\
Colour & 7.50 & 7.30 \\
$\mathrm{pH}$ & 164.0 & 287.90 \\
Conductivity $(\mu \mathrm{s} / \mathrm{cm})$ & 40.82 & 46.44 \\
Porosity $(\%)$ & 0.09 & 0.15 \\
Salinity $(\mathrm{ppt})$ & 1.58 & 1.43 \\
Bulk Density $(\mathrm{g} / \mathrm{cm} 3)$ & Sandy & Sandy Loam \\
Texture & 0.81 & 1.89 \\
TOC $(\%)$ & & \\
Particle size distribution & 99.28 & 89.15 \\
Sand & 0.0 & 10.60 \\
Silt & 0.72 & 0.25 \\
Clay & & \\
\hline
\end{tabular}

Later, $1 \mathrm{~kg}$ each of the reference and mining site soils was weighed separately into clean plastic containers. The mining site soil was diluted 2, 5, 10 times using the reference soil, subsequently dampened with tap water and mixed thoroughly to attain homogeneity. Manual mixing of the soil mixtures continued daily for five days in order to equilibrate and stabilize soil compositions. At each dilution level, mixed soils were weighed into clean labeled plastic containers in five replicates, while the reference soil served as experimental control. Suitable soil dampness that would support survival of worms was determined in a preliminary study. Five worms were introduced into each test jar containing experimental soil mixture, covered with a net-fabricated lid to restrict worms in captivity and monitored closely for a period of ten weeks.

After ten weeks of exposure, each of the test jars was sampled to determine morphology, behaviour and survival of worms. Also, soil samples were taken from test vessels for heavy metal analysis. In brief, soil samples were passed through a sieve having $0.5 \mathrm{~mm}$ pore size, while $0.5 \mathrm{~g}$ of sieved soil was weighed into a glass beaker. Subsequently, a mixture of nitric and perchloric acid (2:1) was added while the contents heated $\left(70^{\circ} \mathrm{C}\right)$ for $30 \mathrm{~min}$ on a hot plate stationed in a fume cupboard. A positive reaction is evident in colour change from brown to colourless. The reaction mixture was made up to $25 \mathrm{ml}$ using distilled water followed by analysis of the digest on Buck Scientific Atomic Absorption Spectrometer, model 210/211 VGP. Metal levels were determined for iron, copper, zinc, lead, cadmium, nickel, chromium and cobalt.

\section{RESULTS AND DISCUSSION}

At the end of worm exposures, metal levels were determined in treatment as well as reference soil samples (Table 2). Chemical analysis revealed that Iron (Fe) was the most abundant while Cadmium (Cd) had the least abundance in the soil mixture (Table 2). In general, metals play biological roles in living organisms when present in trace quantities. However, some of them constitute enormous health threat when present even in moderate levels (Jaishankar et al., 2014). Therefore, threshold levels have been established after considerations of limits that are safe in exposed organisms.

Table 2: Average concentrations $(\mathrm{mg} / \mathrm{kg})$ of heavy metals in various percentages of mining site soil relative to a reference soil in exposure mixtures compared to standards from the European Union (EU), the Federal Ministry of Environment (FME, 2002) and Ministry of Environment, Finland (MEF, 2007).

\begin{tabular}{lllllllll}
\hline Metal & $\mathbf{0 \%}$ & $\mathbf{1 0 \%}$ & $\mathbf{2 0 \%}$ & $\mathbf{5 0 \%}$ & $\mathbf{1 0 0 \%}$ & $\mathbf{E U}$ & FME & MEF \\
\hline Fe & 6338 & 7418 & 6785 & 3693 & 3545 & - & - & - \\
$\mathbf{C u}$ & 44 & 46 & 45 & 42 & 42 & 140 & $70-80$ & $150-200$ \\
$\mathbf{Z n}$ & 41 & 45 & 46 & 41 & 41 & - & $300-400$ & $250-400$ \\
$\mathbf{P b}$ & 16 & 22 & 21 & 21 & 119 & 300 & 1.6 & $200-750$ \\
$\mathbf{C d}$ & 0.7 & 1.0 & 0.8 & 0.8 & 0.6 & 3 & - & $10-20$ \\
$\mathbf{N i}$ & 11 & 11 & 11 & 5.9 & 4.2 & - & - & $100-150$ \\
$\mathbf{C r}$ & 11 & 6.5 & 2.7 & 1.8 & 6.7 & 150 & - & $200-300$ \\
$\mathbf{C o}$ & 6.9 & 7.7 & 5.7 & 2.2 & 13 & - & - & $100-250$ \\
\hline
\end{tabular}

Safety limits are usually determined based on toxicity studies of singular metals following exposure to relevant organisms. Considering that pollutants occur as complex mixtures in environmental matrices (soil, sediment, water, or air), it is important to conduct assessment studies of soil health in a setup that considers several processes of sorption and partitioning, bioavailability, and uptake of substances in living organisms. In this context, mucous lining of worms tend to provide disorptive surfaces that may facilitate pollutant uptake from natural soil. In the soil mixture constituted for this exposure, we noted that mortality of worms increased correspondingly with increasing proportion of mining site soil in exposure vessels (Fig. 2). Mortality of worms was $100 \%$ in four of the five exposure replications (Fig. 2). This outcome is not surprising given that the treatment level is constituted of $100 \%$ mining site soil. On the other hand, the treatment considered to be the least contaminated and comprised $100 \%$ of the reference 
soil, revealed the most conducive soil health and thus recorded the least mortality of worms (Fig. 2).

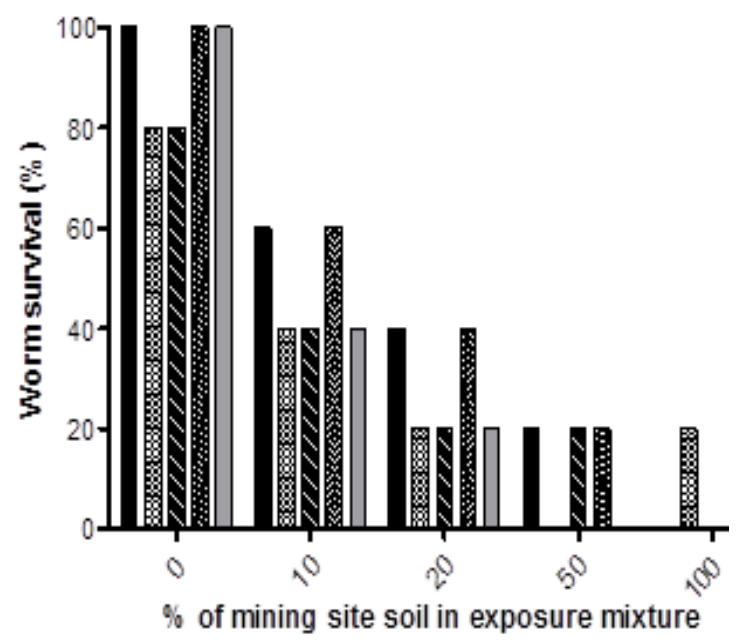

Fig. 2: Survival of earthworm in five replications shown after 70 days of exposure in mining site soil

When one considers that several previous studies spike a singular metal or a simple mixture of metal pollutants on soil, it is evident that this present experiment is a close simulation of conditions in the outer environment, with considerations for ageing and stabilization of constituent soil components (Pachana et al., 2010). Also, it is a close depiction of worm exposures in natural environment where pollutants occur as complex mixtures of different chemical substances. However, the fact that concentrations of most metals determined were within acceptable limits according to several international guidelines, including the European Union, can easily mislead risk assessors on the health of the tested mining site soil (Table 2). Even though chemical analyses were restricted to selected metals with known adverse effects when present in substantial levels, the evidence presented in this study shows that metal levels alone is not a suitable indicator of pollution. In fact, mixtures of different metals, even in low concentrations, can potentially exert deleterious effects in exposed organisms. Other prevailing exposure conditions may have influenced pollutant bioavailability and uptake in organisms, particularly the tendency of worms to facilitate absorption via mucus secretions while in contact with the mining soil. These secretions may influence partitioning of pollutants, sorption and desorption processes in a manner that can promote ion exchange with clay and other components of soil. Meanwhile, assessment of morphology in model organisms is a swift and cost-effective means to determine likely effects due to the presence of heavy metals in the mining site soil. In order to monitor deterioration in health of worms, this study assessed the morphology of organisms at 10 weeks of exposure in different treatment levels. Worms appeared to be bleached, dehydrated and these observations appeared to increase in severity with the proportion of mining site soil and consequent acidity of exposure mixture (Figure 3). Also, exposed worms were sluggish and the resulting effect corresponded with the percentage of mining site soil. These surviving worms curled up at the bottom of test vessels, while worms in control vessels were found in the upper section of soil at the end of a 10 week exposure. On the other hand, worms exposed in $100 \%$ reference soil without the mining site soil appeared healthy and active, which was evident in their active mobility in soil and when taken out of the exposure vessel.

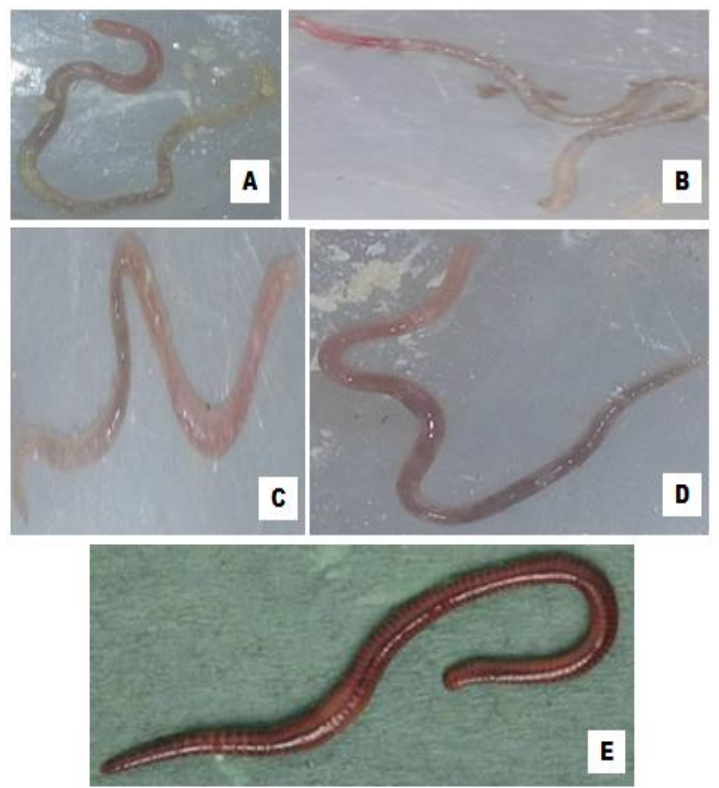

Fig. 3: Morphology of earthworm at the end of a 70 day exposure in mining site soil. Proportion (\%) of mining site soil relative to a reference soil were $100(\mathbf{A}), 50(\mathbf{B}), 20(\mathbf{C}), 10(\mathbf{D})$ and $0(\mathbf{E})$.

Therefore, there is an expected negative impact of mining activity on fertility of agricultural soil. This is because earthworm plays crucial role on soil architecture and aeration. Their burrowing activity contributes to breakdown of organic matter and bioturbation to enhance turnover of organic residue, which in turn influence soil fertility (Guhra et al. 2020). More so, gut microbiomes present in exposed worms may have been negatively affected to impact on exposed organisms and the overall health of the environment. In this context, however, worms are relevant indigenous exposure models and exert biological, chemical and physical impacts on soil and prevailing environmental conditions.

Conclusions: Metal levels were within acceptable limits according to local and international standards; however, they resulted in noticeable negative impacts 
on exposed worms at 10 weeks. Mortality and dehydration of worms increased with the proportion of mining site soil in exposure mixture, but least in the control population. Despite possibility for enrichment of metals in non-target organisms and potential toxicity due to exposure to mining soil, there may be consequences on soil architecture and landscape, crop yield, food quality, water quality and biodiversity.

\section{REFERENCES}

Akande, FO; Ajayi, SA (2017). Assessment of heavy metals level in soil and vegetables grown in PetriUrban farms around Osun State and the associated human health risk.

Int. J. Environ. Agric. Biotech. 2: $3250-3261$.

Chauhan, SS (2010). Mining, development and environment: A case study of Bijolia mining area in Rajasthan, India. J. Hum. Ecol. 31: 65 - 72.

Ezeokoli, OT; Oladipo, OG; Bezuidenhout, CC; Adeleke, RA; Maboeta, MS (2021). Assessing the ecosystem support function of South African coal mining soil environments using earthworm (Eisenia andrei) bioassays (2021). Appl. Soil Ecol. 157: 103771.

Federal Ministry of Environment (FME) Report (2002). Report on studies on the construction of Industrial Effluent Facilities in Kaduna, Nigeria.

Finnish government decree on the assessment of soil contamination and remediation needs.

Ministry of the Environment, Finland, MEF (214/2007, March 1, 2007).

Guhra, T; Stolze, K; Schweizer, S; Totsche, KU (2020). Earthworm mucus contributes to the formation of organo-mineral associations in soil. Soil Biol. Biochem. 145: 107785, doi: https://doi.org/10.1016/j.soilbio.2020.107785.
Jaishankar, M; Tseten, T; Anbalagan, N; Mathew, BB; Beeregowda, KN (2014). Toxicity, mechanism and health effects of some heavy metals. Interdiscip. Toxicol. 7: 60-72.

Markwitz, V; Hein, KAA; Miller, J (2016). Compilation of West African mineral deposits: Spatial distribution and mineral endowment. Precambrian Res. 274: $61-81$.

Mfon, P; Akintoye, OA; Mfon, G; Olorundami, T; Ukata, SU; Akintoye, TA (2014): Challenges of deforestation in Nigeria and millennium development goals. Int. J. Environ. Bioener. 9: 76 -94 .

Olade, MA (2019). Solid mineral deposits and mining in Nigeria: A sector in transitional change. Achievers J. Sci. Research 2: 1-15.

Pachana, K; Wattanakornsiri, A; Nanuam, J (2010). Heavy metal transport and fate in the environmental compartments. NU Sci. J. 7: 1-11.

Scullion, J (2002). Soil degradation and recovery following surface mining. Rubio, JL; Morgan, RPC; Asins, S; Andreu, V (Ed.). International congress of the European society for soil conservation, Valencia, Spain, 2: 1265 - 1276.

Sidhu, GPS (2016). Heavy metal toxicity in soils: sources, remediation technologies and challenges. Adv. Plants Agric. Res. 5: 00166. DOI: 10.15406/apar.2016.05.00166.

Yvan, C; Stephane, S; Stephane, C; Pierre, B; Guy, R; Hubert, GB (2012). Role of earthworms in regenerating soil structure after compaction in reduced tillage systems. Soil Biol. Biochem. 55: $93-103$. 